Reseñas

\title{
Un modelo de negocios especial: la franquicia social
}

\author{
A special business model: the social franchise \\ Um modelo de negócio especial: a franquia social \\ Máximo Eduardo León Medina \\ Universidad de Guadalajara, México \\ maximo.leon9413@alumnos.udg.mx \\ https://orcid.org/0000-0002-9689-3012 \\ Cándido González Pérez \\ Universidad de Guadalajara, México \\ cgonzalez@cualtos.udg.mx \\ https://orcid.org/0000-0003-4876-5734
}

\section{Resumen}

El propósito de las siguientes líneas es reseñar el libro Migrantes exitosos: la franquicia social como modelo de negocios, editado por la Universidad de Guadalajara, donde se compilan seis excelentes trabajos elaborados con alta rigurosidad. La compilación de la obra está a cargo de Patricia Arias. Sus principales características son su fortaleza teórica y el haber sido escrita principalmente por mujeres. Además, las descripciones del trabajo de campo realizado en cada uno de los casos son claras y metodológicamente correctas. Con este libro se abre un nuevo abanico para el análisis de los modelos de negocios en el área de las ciencias sociales.

Palabras clave: franquicia social, migración, modelo de negocio, trabajo. 


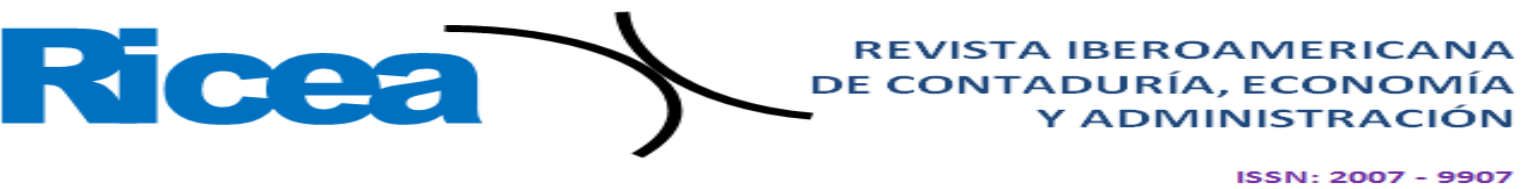

\section{Abstract}

The purpose of the following lines is to review the book Successful Migrants: The Social Franchise as a Business Model, published by the University of Guadalajara, where six excellent works prepared with high rigor are compiled. The compilation of the work is in charge of Patricia Arias. Its main characteristics are its theoretical strength and the fact that it was written mainly by women. Furthermore, the descriptions of the field work carried out in each of the cases are clear and methodologically correct. This book opens a new range for the analysis of business models in the area of social sciences.

Keywords: social franchise, migration, business model, work.

\section{Resumo}

O objetivo das seguintes linhas é fazer uma resenha do livro Migrantes de sucesso: a franquia social como modelo de negócio, publicado pela Universidade de Guadalajara, onde se compilam seis excelentes trabalhos elaborados com alto rigor. A compilação da obra está a cargo de Patricia Arias. Suas principais características são a força teórica e o fato de ter sido escrito principalmente por mulheres. Além disso, as descrições dos trabalhos de campo realizados em cada um dos casos são claras e metodologicamente corretas. Este livro abre um novo leque para a análise de modelos de negócios na área das ciências sociais.

Palavras-chave: franquia social, migração, modelo de negócios, trabalho.

Fecha Recepción: Mayo 2021 Fecha Aceptación: Octubre 2021

\section{Introducción}

Existe gran diversidad de modelos de negocios, y la mayoría de autores cuando se refieren a ellos priorizan los que están relacionados con lo más avanzado de la tecnología computacional. De hecho, parece lugar común el pensar que todo lo relacionado con la creación de nuevas empresas debe pasar por ese crisol: las aplicaciones electrónicas (Rubí y Sucre, 2020). Sin embargo, con la aparición del libro Migrantes exitosos: la franquicia social como modelo de negocios — coordinado por Patricia Arias (2017) — se abre un camino diferente para el análisis de las empresas. 


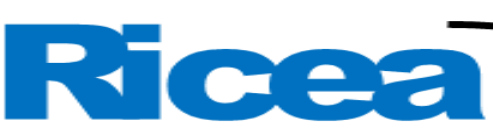

REVISTA IBEROAMERICANA DE CONTADURÍA, ECONOMIIA YADMINISTRACIÓN

ISSN= $2007-9907$

La franquicia social aparece como una categoría teórica muy interesante y con gran respaldo de información, como lo demuestran los autores. Lo que se conoce comúnmente como franquicias es lo relacionado al pago para poder utilizar una marca, por ejemplo Oxo, Seven Eleven, Walmart o Burguer King, pero el término franquicia social es nuevo y sirve para explicar que el utilizar comercialmente el nombre no es solo asunto de logotipos, sino también de experiencias y conocimientos que se transmiten entre generaciones.

La franquicia social es una práctica cultural que se ha utilizado ancestralmente aunque no se había analizado con fines académicos. Los casos que se detallan en la publicación explican de manera desmenuzada cómo las prácticas laborales se van enseñando con el ejemplo y, en no pocos casos, en meses de actividades en los lugares donde expanden sus negocios. La franquicia social es aprender, construir, expandir, enseñar, colaborar y "mandar a traer" otros miembros de la familia para incorporarlos. La franquicia social es historia, es una repetición de costumbres de personas con orígenes humildes que han encontrado una manera de sobrevivir o de vivir con gran holgura económica; es una nueva forma de modelo económico que se ha repetido en algunos casos por más de cuatro generaciones.

La relevancia social que representa este tipo de franquicias es evidente en las poblaciones de origen porque una de sus principales características es el continuo retorno de los iniciadores. Las fiestas patronales, por ejemplo, son la ocasión para el retorno cíclico anual para demostrar (presumir) los logros económicos. En los agradecimientos al Santo Patrono se dejan ver y también ahí contratan a los nuevos trabajadores-socios en las ampliaciones económicas. La franquicia social hace posible la incorporación de familiares, ahijados y paisanos (en ese orden).

\section{Metodología}

La metodología utilizada en el libro reseñado son entrevistas en profundidad, con visitas de trabajo de campo muy extensas, revisiones bibliográficas para sustentar las bases teóricas y análisis etnográfico de las fiestas religiosas en las poblaciones de origen. Un aspecto metodológico que cabe resaltar en el análisis de la franquicia social es la constante autoexplotación, porque de ahí proviene su fuente de éxito económico. Dicho en otras palabras, el hacer disminuir los costos de producción a través de la disminución del capital variable (trabajo) es más competitivo y es más difícil que la competencia los elimine del mercado. 


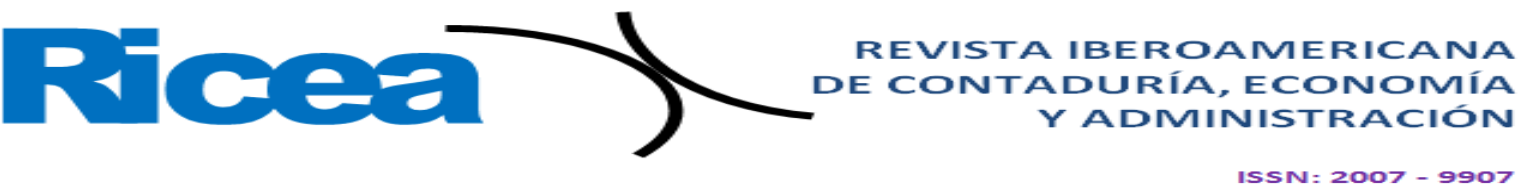

Algo similar llevan a cabo con respecto al capital constante (edificios, maquinaria y equipo): invierten lo menos posible y ellos mismos producen parte de lo requerido. Es decir, habitan los espacios laborales para disminuir costos y evitan pagos de transportación utilizando sus propios medios. Las historias muy bien documentadas de cada uno de los seis casos corresponden a grupos que tienen como características el haber iniciado desde los niveles más bajos de las clases sociales.

Es bien conocido en México que la mayoría de los empleos se generan en la pequeña y mediana empresa, de ahí que sea donde se ubican las experiencias de la franquicia social. Los trabajadores que adquieren los conocimientos y las habilidades necesarias para el desarrollo de una empresa en el núcleo familiar (los teóricos le llaman capital social) han jugado un papel de primer orden en la generación nacional de ingresos (producto interno bruto).

\section{Desarrollo}

Los casos que se analizan en el libro Migrantes exitosos... corresponden, en primer lugar, a los paleteros de Mexticacán, donde se refleja el profundo abandono del municipio, ubicado en la región de los Altos de Jalisco, en los límites con Zacatecas. Es un municipio pequeño con no más de 7697 habitantes en el año de 1963 (fecha de realización del estudio), donde la principal actividad económica era la agricultura y la ganadería, actividad propiedad de los pocos favorecidos y fuente de empleo del resto de la población. En este ambiente, se favoreció la migración por la falta de oportunidades, pero al mismo tiempo algunos habitantes desarrollaron un sentido empresarial en momentos de limitación de recursos económicos.

Así surgieron las actividades empresariales que se muestran en la obra. Los antecedentes fueron la elaboración de dulces y el negocio de venta de paletas en los cines ambulantes (esto durante la década de 1940-1950); posteriormente, el negocio que detonó y del cual se centra el caso fue el de las paletas en otras ciudades. Se sabe que Ángel González fue uno de los iniciadores al establecer su primer negocio en Aguascalientes. Allí experimentó con una novedad: en lugar de esperar que los clientes acudieran al negocio, él los buscaba en la calle y construyó su primer carro de paletas refrigerado y con llantas. Le fue bien con su manera de abrir nuevos caminos y solicitó a los hermanos Martínez que, además de producir las paletas, crearan equipos refrigerantes para expandir sus ventas. 


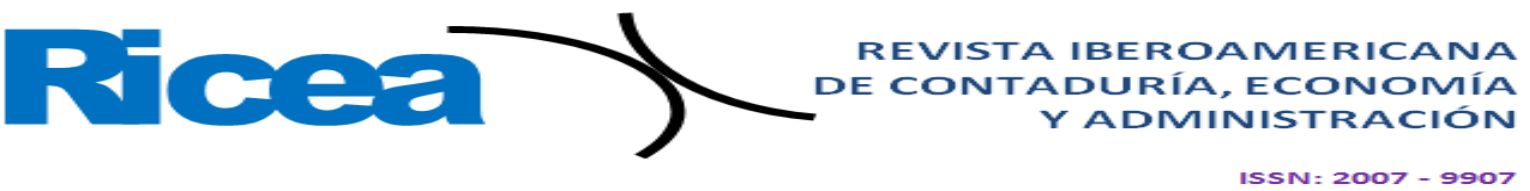

Los negocios fueron proliferando y al poco tiempo contaba con más de una treintena de paleterías con sus respetivos equipos. El siguiente paso fue contratar personas originarias de Mexticacán — primero familiares (hombres únicamente)—, luego de la familia más extendida (compadres, ahijados) y al agotar el círculo pequeño empezó a contratar a simples paisanos. Para ahorrar, los trabajadores dormían en los negocios y posteriormente se hacían socios de la empresa. En lugar de trabajadores, tenía socios y eso resultó ser muy exitoso. No siguió un patrón, pues algunos eran socios en diferentes proporciones, mientras que otros eran simples trabajadores (siempre se buscaba que fueran originarios de Mexticacán). Les proporcionaba diferentes formas de financiamiento, que podría ser un simple préstamo, luego vendía equipo a cambio de trabajo y se repartían el mercado en forma estratégica. Donde las ventas no eran redituables, se cerraba y se buscaba un nuevo espacio.

La presencia de paleterías — cuyo origen se halla en Mexticacán — se ha extendido por la mayor parte de la república mexicana y han mantenido un sistema eficiente de reparto de insumos y equipos. En este contexto, las relaciones familiares se han consolidado porque la mayoría acude cada año a las fiestas patronales.

El segundo caso lo constituye la población de Juanchorrey, Zacatecas, un poblado dedicado a la elaboración de tortillas. En los inicios fue en Torreón, Coahuila, donde los primeros juanchorreyenses incursionaron en el negocio. Primero Juan Gámez con la ayuda de Melesio Nava crearon un pequeño puesto de tortillas y posteriormente dieron un salto cualitativo cuando inauguraron su primera tortillería (llamada La Bola) en el año de 1951.

En la década de los años cincuenta se dio un fuerte impulso a la producción de tortilla en toda la república, principalmente en las zonas urbanas, porque el trabajo de los obreros exigía que sus esposas no dedicaran mucho tiempo a la producción de nixtamal y las visitas a los molinos. Se fue imponiendo la moda de comprar el producto ya elaborado y las tortillerías fueron creciendo exponencialmente.

El crecimiento poblacional y el desarrollo de diversas ciudades en crecimiento del país favorecieron la proliferación de este tipo de empresas. En ese tiempo — según se narrael crecimiento de las ciudades tenía relación directa con la injerencia del gobierno mexicano, lo que propició el desarrollo en ciertas regiones, aunque con la imposición de ciertas medidas y regulaciones.

La situación cambió el año de 1992 con la entrada del sistema neoliberal que abrió la competencia y permitió el libre mercado. Esto impactó de manera directa a la industria de la 


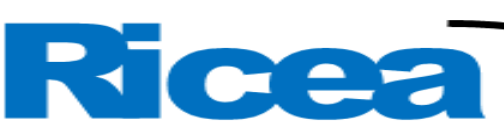

REVISTA IBEROAMERICANA DE CONTADURÍA, ECONOMÍA YADMINISTRACIÓN

ISSN= $2007-9907$

tortilla, por lo cual los juanchorreyenses se organizaron en una primera instancia como la Unión de Molineros y posteriormente en el año 2006 conformaron a Unión Nacional de Industriales de la Masa y la Tortilla. El éxito de este modelo de negocio - tema cultural porque la tortilla es un elemento primordial en la gastronomía mexicana - se ve reflejado en la fiestas de Juanchorrey, ya que — como se explica en el libro- cada año se elige al empresario que organizará las festividades, para lo cual debe invertir grandes cantidades de dinero.

La fiesta cobra relevancia en el modelo de negocio, ya que reúne a los empresarios más importantes de la industria de la tortilla, la mayoría originarios del poblado aunque sus actividades se desarrollen en otros lugares. El motivo de la fiesta es conocer a las personas del medio para establecer relaciones que puedan unir a las familias, lo cual sirve para el crecimiento de la industria y para mantenerse vigentes en el mercado. Es muy conocido que en las fiestas patronales hacen rifas de equipos de tortillerías para apoyar la realización de las festividades, pero siempre ligado a su ámbito laboral.

El tercer caso corresponde a los taqueros de Santiaguito de Velázquez, una delegación del municipio de Arandas. Los pioneros se vieron obligados a dejar sus casas y sus siembras porque los cristeros "habían hecho cuartel” en su localidad y ellos salieron huyendo. Fueron a la ciudad de México y al principio se dedicaban a la venta de fruta picada, pero de alguna manera cambiaron de giro porque incursionaron en el negocio de la venta de huesos: compraban cabezas en el rastro, las cocían para retirar la carne y luego comercializaban el hueso. En alguna ocasión —debido al olor que despedía la carne que se retiraba del huesose pensó en dar un tratamiento posterior. Después de muchos experimentos, incluido el de poner un bote con agua bajo el recipiente donde se hacían los trabajos, crearon los tacos de cabeza. Los mantenían siempre calientes por el vapor que le agregaban. Tuvieron mucho éxito y después su principal objetivo fue crear las mejores salsas, lo que constituye su principal atractivo y distinción.

De manera similar a los paleteros de Mexticacán, contrataban a familiares y después de ellos a otros habitantes de Santiaguito de Velázquez. Se han expandido tanto por toda la república y han hecho tanta fortuna que desde hace muchos años el principal atractivo ha sido presumir quién cuenta con la mejor casa en la población y el mausoleo más llamativo. Se invierten altas cantidades de dinero en la construcción de edificios que se habitan una o dos semanas al año en la época de las fiestas patronales. Como caso anecdótico, en algunas 


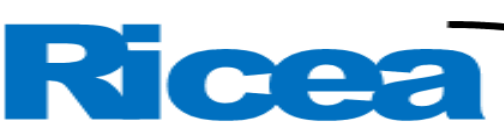

REVISTA IBEROAMERICANA DE CONTADURÍA, ECONOMÍA YADMINISTRACIÓN

ISSN= $2007-9907$

ocasiones en los fuegos artificiales se hacen volar dólares para que de forma lúdica los visitantes los puedan recoger. Incluso se tiene el conocimiento de que desde los años sesenta incursionaron en el mercado estadounidense, principalmente en el estado de Texas.

La franquicia social, en este caso, ha tomado forma en cuanto a que los nuevos trabajadores van adquiriendo los conocimientos, habilidades y destrezas de lo que se requiera para la elaboración de tacos de cabeza. Luego abren ellos sus propios negocios con préstamos que les facilitan quienes los invitaron a incursionar en la empresa. Para el análisis particular del papel de los préstamos en este tipo de modelo de negocios, se recomienda la lectura del trabajo de Salazar (2021).

Sin embargo, el ascenso de las mujeres ha sido más lento que el de hombres, pues siempre ha habido preferencia por los varones. Los descendientes de los primeros taqueros han heredado la fortuna, pero no la tradición de regresar a Santiaguito de Velázquez a las fiestas patronales de diciembre. En otras palabras, ellos ya son originarios de otras ciudades, por lo que las enormes casas seguirán estando deshabitadas.

El cuarto caso corresponde a los abarroteros de San Ignacio Cerro Gordo. La franquicia social en este caso consiste en participar como arrendatarios, trabajadores o encargados de tiendas de abarrotes. Desde el año 2000 los empresarios de San Ignacio se han diseminado por toda la república y se cuenta con información de que son propietarios de más de tres centenas de establecimientos.

Los iniciadores han seguido las mismas normas no escritas de los tortilleros de Juanchorey, de los taqueros de Santiaguito de Velázquez y de los paleteros de Mexticacán: iniciar con un nuevo negocio, la autoexplotación de los trabajadores familiares, el ahorro en el pago de vivienda y, en este caso, la venta a crédito y al detalle. En muchos casos adquieren tiendas de abarrotes que van en declive, abren en horarios más amplios (autoexplotación), venden cigarros en piezas y otorgan créditos a los vecinos; preparan lonches para los trabajadores del entorno y arman piezas que adquieren en partes para vender productos completos.

Los espacios que cubren son las áreas pobres de las grandes y medianas urbes porque ahí es donde viven las familias que prefieren comprar al detalle sin desembolsar inmediatamente el pago. A diferencia de los casos explicados con anterioridad, el trabajo en las tiendas sí requería de mayor presencia de las mujeres, ya sea como empleadas, propietarias o acompañantes de los hombres para hacer las labores del hogar. El éxito ha 


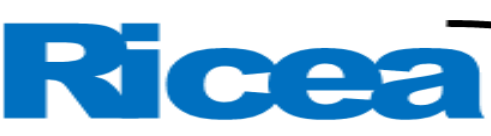

REVISTA IBEROAMERICANA DE CONTADURÍA, ECONOMÍA YADMINISTRACIÓN

ISSN= $2007-9907$

residido en los créditos blandos que se hacen entre los miembros de sus familias, compadres o - en el último de los casos — paisanos. Se les invita como trabajadores, pueden ascender a copropietarios y luego a propietarios. El proceso se repite y de esta manera se van incorporando nuevos empresarios que abarcan rutas no cubiertas.

Los vendedores de fruta en la zona metropolitana de Guadalajara representan el penúltimo de los casos de la aplicación de la franquicia social como modelo de negocio. Los promotores son indígenas nahuas provenientes de la huasteca de Hidalgo, quienes se han ubicado en los lugares más alejados y pobres de la ciudad para ahorrar en pagos de instalación. Al respecto, se recomienda la lectura de Rodríguez Herrera (2020).

A los recién llegados se les apoya con no pagar renta y solo la mitad del costo de la electricidad. Una vez asentados —y puesta en marcha su empresa—, traen familiares para ampliar el espectro de atención. Cuando han cubierto el abanico de familiares añaden a compadres y amigos, igual que lo descrito en los casos anteriores. Todos aprenden en el picado de la fruta y arman carritos similares que son transportados en camionetas a los lugares donde ofrecen su mercancía.

El fenómeno inició en la década de los noventa del siglo pasado y se cuentan por decenas. Pueden llegar a más de dos centenas de integrantes. Dos características propias de este grupo es que por tratarse de una comunidad indígena están más aislados que los otros grupos y por razones sociales tienden a mantenerse unidos; la otra es que se trata de personas cuya máxima aspiración es subsistir, por lo que no se busca la creación de riqueza como en los casos anteriores.

Los muebleros de Capacuaro representan el último de los ejemplos expuestos en el libro. Es otro grupo de indígenas que producen muebles de baja o regular calidad que venden a las amplias capas de la clase media de la zona metropolitana de Guadalajara. De manera similar a los vendedores de fruta, ellos viven en grupos compactos en las orillas de Guadalajara y Zapopan. Traen familiares para aprender del oficio y de las ventas. Al principio son trabajadores, luego copropietarios y finalmente crean su propio negocio. A diferencia de los anteriores - y por constituir el grupo más pequeño-, el nivel de desarrollo ha provocado que participen pocos miembros de la familia y no han rebasado ese nivel hasta la fecha. Son pocas decenas y vinieron a Jalisco a finales del siglo pasado. 
En definitiva, se puede afirmar que el libro reseñado en el presente documento (el cual también se encuentra en versión electrónica) es muy recomendable para estudiantes, profesores y público en general, pues su lectura es sencilla y su lenguaje accesible.

Tabla 1. Concentrado de información

\begin{tabular}{|c|c|c|c|c|c|c|}
\hline $\begin{array}{l}\text { Pregunta/franquici } \\
\text { a }\end{array}$ & Paletería & $\begin{array}{l}\text { Tortillerí } \\
\text { a }\end{array}$ & $\begin{array}{l}\text { Taquerí } \\
\text { a }\end{array}$ & $\begin{array}{l}\text { Abarrotero } \\
\mathrm{s}\end{array}$ & $\begin{array}{l}\text { Frutero } \\
\mathrm{S}\end{array}$ & $\begin{array}{l}\text { Mueblero } \\
\text { s }\end{array}$ \\
\hline $\begin{array}{l}\text { ¿Producen algunos } \\
\text { de sus insumos? }\end{array}$ & Sí & Sí & Sí & Sí & Sí & Sí \\
\hline $\begin{array}{lr}\text { ¿Contratan } & \text { a } \\
\text { familiares } & \text { y/o } \\
\text { paisanos? } & \end{array}$ & Sí & Sí & Sí & Sí & Sí & Sí \\
\hline $\begin{array}{l}\text { ¿Han utilizado sus } \\
\text { empresas como } \\
\text { dormitorio para } \\
\text { ahorrar en gastos? }\end{array}$ & Sí & No & Sí & Sí & No & No \\
\hline $\begin{array}{l}\text { ¿Su mercado } \\
\text { abarca más de la } \\
\text { mitad del territorio } \\
\text { nacional? }\end{array}$ & Sí & Sí & Sí & Sí & No & No \\
\hline $\begin{array}{l}\text { ¿Regresan cada } \\
\text { año a las fiestas } \\
\text { patronales? }\end{array}$ & Sí & Sí & Sí & Sí & Sí & No \\
\hline $\begin{array}{l}\text { Número } \\
\text { aproximado de } \\
\text { generaciones } \\
\text { familiares que } \\
\text { abarca }\end{array}$ & Cuatro & Cuatro & Cinco & Una & Dos & Dos \\
\hline $\begin{array}{lr}\text { ¿Requiere } & \text { mayor } \\
\text { presencia } & \text { de } \\
\text { hombres } & \text { o } \\
\text { mujeres? } & \end{array}$ & $\begin{array}{c}\text { Hombre } \\
\text { s }\end{array}$ & Hombres & $\begin{array}{c}\text { Hombre } \\
\mathrm{s}\end{array}$ & Mujeres & $\begin{array}{c}\text { Mujere } \\
\text { s }\end{array}$ & Mixto \\
\hline
\end{tabular}


Fuente: elaboración en base a los datos obtenidos directamente del libro "Migrantes exitosos: la franquicia social como modelo de negocios."

\section{Conclusiones}

Consideramos que con la publicación de obras como la compilada por Patricia Arias se amplía el panorama para los expertos en análisis de negocios porque, primero, la óptica de la franquicia social es novedosa en estos ámbitos; segundo, porque es poco común realizar trabajo de campo en aspectos históricos y sociales de pequeños grupos de productores y, tercero, porque generalmente se ha considerado como modelos de negocio a los basados en las nuevas tecnologías, desdeñando con ello a los que se han desarrollado por tres, cuatro o más generaciones, donde la transmisión de conocimientos y habilidades se originan en la familia.

La franquicia social requiere de la elaboración acuciosa de análisis particulares como los expuestos en la obra reseñada. De hecho, se debe escudriñar en cada caso sobre la autoexplotación económica, los conocimientos particulares que se van pasando de generación a generación y con estricto orden de cercanía familiar, la participación de las mujeres (hay casos hoy en día en donde se les está vedado el ingreso), la utilización de los espacios laborales como dormitorios para ahorrar en gastos, los retornos cíclicos para “demostrar” que los negocios han sido prósperos, la reproducción entre generaciones, etc. 


\section{Referencias}

Arias, P. (coord.) (2017). Migrantes exitosos: la franquicia social como modelo de negocios. México: Universidad de Guadalajara.

Rodríguez Herrera, J. A. (2020). Las actividades comerciales de migrantes mazahuas en Aguascalientes, México (1970-2020). Odisea, Revista de Estudios Migratorios, (7).

Rubí, L. y Sucre, G. (2020). Servicios basados en el conocimiento (SBC) como modelos de negocios de organizaciones inteligentes. Revista Electrónica LAC (Los Agentes del Cambio), 6, 45-61.

Salazar, L. (2021). Del crédito nos sostenemos, porque de contado nomás no. Un caso etnográfico de la deuda en la costa de Nayarit, México. Antropología y Etnografía, $6(1)$. 